\title{
Residual Stress, Microstructure and Hardness of Thin-Walled Low-Carbon Steel Pipes Welded Manually
}

\author{
Cleiton Carvalho Silva ${ }^{a}$, Joaquim Teixeira de Assis ${ }^{b}$, Sergey Philippov ${ }^{c}$, Jesualdo Pereira Farias ${ }^{a}$ \\ ${ }^{a}$ Departamento de Engenharia Metalúrgica e de Materiais, Laboratório de Pesquisa e Tecnologia em \\ Soldagem - LPTS, Universidade Federal do Ceará - UFC, Campus do Pici, s/n, Bloco 1080, 60455- \\ 760, Fortaleza, CE, Brazil \\ ${ }^{b}$ Departamento de Engenharia Mecânica, Instituto Politécnico de Nova Friburgo - IPRJ, Nova \\ Friburgo, RJ, Brazil \\ 'Research Laboratory "Research and Simulation of Metallic Materials Structure and Properties", \\ St-Petersburg State Politechnical University, 195251, Saint-Petersburg, Russia
}

Received: March 12, 2016; Revised: June 6, 2016; Accepted: August 10, 2016

The aim of this work is to evaluate the welding residual stress profile in ASTM A106 Gr. B steel pipes with 4" diameter and to correlate this profile with the microstructure and hardness of the joint. The results showed that the residual stresses are more uniform for a lower welding heat input. Higher welding heat input causes not only a non-uniformity of the stress profile but also promotes the maximum stress as high as the yield strength. The microstructure was composed of ferrite, perlite and possibly bainite; the presence of martensite was not verified. The hardness results indicated that none of the welding parameters used produced levels of hardness greater than $249 \mathrm{HV}$. Such a result is of fundamental importance because it suggests that low hardness does not necessarily mean low residual stress levels.

Keywords: Welding, Residual stress, Microstructure, Hardness, Steel pipes

\section{Introduction}

Industrial pipes are very important for fluid transportation in the chemical, petrochemical, nuclear and petroleum industries. To assure the integrity of weld joints, the correct welding parameters/procedures must be selected to prevent the formation of defects, as well as to eliminate possible defects introduced by the welding ${ }^{1-3}$. Most defects can be detected by non-destructive techniques ${ }^{4-7}$. The elimination of defects in welds contributes significantly to assure a good performance. However, some kinds of failure do not depend on preexisting defects and the vectors associated to the failure are generally difficult to be detected and it is not always possible to eliminate them, such as residual stresses, for example.

Residual stresses are defined as those stresses which are retained within a body when no external loads are acting. Residual stresses can have many different origins, but are always the result of some form of misfit; either between different parts, different regions within the same part, or even different phases within a microstructure ${ }^{9}$. In welding, residual stresses arise due to the expansion and contraction of the weld metal (WM) and adjacent base metal (heat affected zone - HAZ) during local heating and subsequent cooling ${ }^{10}$.

Among the more important types of failure, which frequently occur in industrial pipes, are fatigue and stress

* e-mail: cleiton@metalmat.ufc.br corrosion cracking (SCC). The main factors associated to fatigue damage in welded structures, industrial equipment and pipelines are residual stress, stress concentration and the mechanical properties of the material, which are commonly dependent on the macro- and microstructures ${ }^{11}$. Stress corrosion cracking usually occurs due to a special combination of the following factors: material corrosivity, the environment to which the components are exposed and the presence of tensile stress, including residual stress. This last factor becomes very critical for stress-corrosion cracking when welding is a main manufacturing process of the structure or component. In addition, to improve the material corrosivity and to control the environmental conditions during operation is difficult ${ }^{11-17}$. Stress corrosion cracking has been one of the most serious problems for the production of petroleum and in refineries, where the presence of $\mathrm{H}_{2} \mathrm{~S}$ makes the fluid extremely corrosive ${ }^{18,19}$. Welding, as the main manufacturing process applied to the assembly and repair of pipes and tubes provides a favorable condition for fatigue and SCC failures, due to presence of tensile residual stress in the welded joints.

Consequently, thin-walled pipes have become under intense study due to their wide use in refineries and offshore platforms. Much effort has been centered on through-thickness residual stress profile evaluation using computational methods, since it is not possible to determine the residual stress profile on the inner surface due to equipment access difficulties ${ }^{20-23}$. Most of these works have demonstrated that the residual 
stresses change almost lineally through the thickness and the maximum stress value on the inner surface is similar to outer surface levels, however with tensile stresses on the inner surface and compressive stresses on the outer surface in the weld zone ${ }^{24-26}$.

Lee and Chang ${ }^{27}$ mentioned in their work on the numerical simulation of residual stress in pipes that for thin-walled pipes, the heat deposited during circumferential butt welding is high enough to result in an uniform temperature increase through the pipe thickness at the weld. In this case, the circumferential strain due to the radial expansion and subsequent contraction will be the only deformation that will create thermal stresses. The circumferential shrinkage causes a local inward deformation in the vicinity of the weld, named "tourniquet effect" 20,24 , which generates a bending moment. This means that tensile axial residual stresses are produced on the inner surface balanced by compressive stresses on the outer surface. Tensile axial residual stresses are formed on the outer surface away from the weld centre-line, and compressive axial residual stresses on the inner surface ${ }^{27}$.

The ASME code has recommended that the residual stress magnitude on outer and inner surfaces should be considered the same as the yield strength of the material in the weld zone (WM and HAZ) for thin-walled pipes. In addition, it considers also that the tensile stresses, which are present on the inner surface and the stress on outer surfaces, which are compressive, should be considered as having a linear distribution of residual stress through-thickness ${ }^{28}$.

Although advances have been made on welding residual stress in thin-walled pipes, few works have evaluated the effect of welding parameters/procedures on residual stress, or the residual stress, mechanical properties and microstructure relationships. Silva et al. ${ }^{29,30}$ evaluated the behavior of welding residual stress of thin-walled pipes with 2" diameter and found high levels of stresses in the FZ and HAZ. International standards and codes of pipe assembly and repair associate the hardness of WM and HAZ with the possibility of SCC failure. They have established that materials that have hardnesses above $248 \mathrm{HV}^{31,32}$ or 250 $\mathrm{HV}^{33,34}$ possess high susceptibility to this type of failure. Some works have reported the occurrence of such failures in crude oil pipes and gas pipes ${ }^{35,36}$ but the cracks were in low hardness regions with hardness values below the standard critical value established.

This work aims to present some experimental results concerning the effect of the welding heat cycle on residual stress behavior, microstructural changes and hardness of the butt-welded joints in ASTM A106 Gr. B thin-walled pipes with 4" diameter welded manually using the GTAW process. The proposal is to evaluate the relation between welding residual stress and hardness of welds and the effective role of hardness as a parameter to assess the stress corrosion cracking susceptibility.

\section{Experimental procedure}

ASTM A106 Gr. B steel tubes with a $101.6 \mathrm{~mm}$ (4 in.) diameter and $6.6 \mathrm{~mm}$ thickness were used in this work. A semi-V joint with a $35^{\circ}$ angle and root opening of $6 \mathrm{~mm}$ was made. The filler metal used was an AWS E70-S3 steel. The chemical composition and mechanical properties of the materials (pipe and filler metal) are shown in Tables 1 and 2. The joints were made by machining a bevel geometry of the semi-V type (Figure 1), the dimensions of which are in Table 3. The welds using the GTAW process were carried out manually, the parameters of which are presented in Table 4. The pipes were welded by three pass welding: root, filler and finishing. Eight test samples were prepared, four under the same high heat input conditions and welding parameters (A1-A4), and four with low welding heat input conditions (B1-B4). Four samples form each set were prepared to check the repeatability of behavior of the residual stresses for technically similar welding parameters.

The X-ray tensiometry method employed at present study to determine the residual stresses was the " $\sin ^{2} \psi$ method", which is commonly applied to polycrystalline materials ${ }^{37}$. Based on the position of the peak diffraction, it is possible to determine the spacing of the crystal planes $\left(\mathrm{d}_{\mathrm{hk}}\right)$, by means of Bragg's Law (Equation (1)). Using this equation, it is possible to correlate the $2 \theta$ diffraction angle measured experimentally with the interplane distance $\mathrm{d}_{\mathrm{hkl}}$, where $\lambda$ is the X-ray wavelength ${ }^{38}$.

$$
n \lambda=2 d_{h k l} \operatorname{sen} \theta
$$

Since the immense majority of materials are polycrystalline with a random crystal orientation, except when materials have crystallographic texture. Therefore, considering a stress-free material, the interplanar distance is standard $\left(\mathrm{d}_{0}\right)$, however for a material subjected to stresses (applied or residual), the interplane distance will be subject to variations in accordance with the orientation (angle $\psi$ ) of the family of hkl planes and the stress applied ${ }^{39}$, as shown in Figure 2.

As a result, an X-ray scan inclined at a given angle over the surface of a polycrystalline material will only be diffracted by a few grains with a favorable orientation. Thus, applying Bragg's Law it is possible to find the $d_{h k l}$ for each angle $\psi$. According the $\sin ^{2} \psi$ method theory, to calculate the stresses using this method, variations in the interplanar distance needs to be determined as a function of the variation in the $\psi$ angle (Figure 2), and based on equation (2) the stress is then calculated ${ }^{38}$. More details about the X-ray tensiometry theory and equationing may be found in Noyan and Cohen ${ }^{37}$.

$$
\sigma=-\frac{E}{1-v} \cot g \theta \frac{d \theta}{d\left(\operatorname{sen}^{2} \psi\right)}
$$


Table 1: Chemical composition of base and filler metals. (wt.\%)

\begin{tabular}{lccccc}
\hline Material & C & Mn & Si & P & 0.016 \\
ASTM A106 Gr. B (pipe) & 0.19 & 0.96 & 0.20 & 0.006 \\
Filler metal AWS ER 70 S3 & 0.18 & 0.95 & 0.18 & 0.09
\end{tabular}

Table 2: Mechanical Properties of the materials.

\begin{tabular}{lccc}
\hline Material & Yield strength $\sigma_{\mathrm{y}}(\mathrm{MPa})$ & Tensile strength $\sigma_{\mathrm{R}}(\mathrm{MPa})$ & 316 \\
\hline Filler metal & 420 & 512 & 33 \\
Pipe & 357 & 415 & 23 \\
Standard of pipe (Min.) & 241 & $33)$ & 23 \\
\hline
\end{tabular}

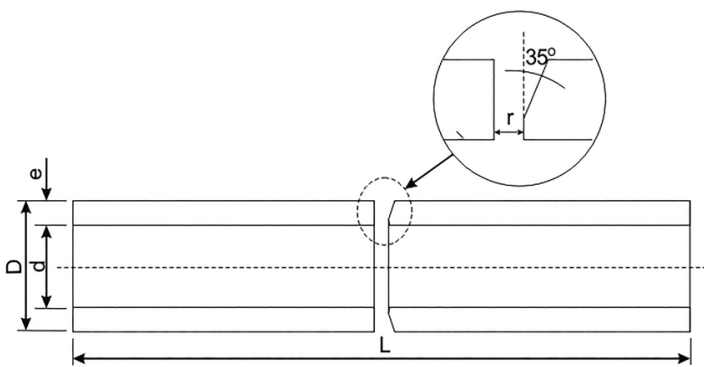

Figure 1: Schematic draw of test bodies and detail of the joint geometry.
The stress measurements were carried out using a portable X-ray mini-diffractometer for field measurements (Figure 3) that was developed by the IPRJ-Instituto Politécnico de Nova Friburgo (Polytechnic Institute of Nova Friburgo). This equipment has been used successfully for the measurement of residual stresses ${ }^{40,41}$. A monochromatic beam with $\mathrm{Cr} \operatorname{K} \alpha$ radiation $(\lambda=2.2911$ $\AA$ ) and the diffraction for the crystallographic planes family $\{211\}$ were used in this work. Only the axial residual stresses were measured, not only because these are the most important in relation to the beginning and

Table 3: Test body dimensions and joint geometry.

\begin{tabular}{lccccc}
\hline Dimensions (in) & $\mathrm{D}(\mathrm{mm})$ & $\mathrm{d}(\mathrm{mm})$ & $\mathrm{e}(\mathrm{mm})$ & $\mathrm{L}(\mathrm{mm})$ & $\mathrm{r}(\mathrm{mm})$ \\
\hline $4^{\prime \prime}$ & 128.2 & 114.3 & 6.6 & 818.8 & 6 \\
\hline
\end{tabular}

Table 4: Welding parameters.

\begin{tabular}{|c|c|c|c|c|c|}
\hline Sample & Pass & Current (A) & Voltage (V) & Welding speed $(\mathrm{cm} / \mathrm{min})$ & Welding heat input $(\mathrm{kJ} / \mathrm{cm})$ \\
\hline \multirow{3}{*}{ A1 } & Root & 98.2 & 10.9 & 3.9 & 10.6 \\
\hline & Filler & 102.3 & 11.2 & 3.2 & 13.8 \\
\hline & Finishing & 101.9 & 11.1 & 3.1 & 14.5 \\
\hline \multirow{3}{*}{ A2 } & Root & 103.1 & 11.0 & 3.4 & 12.9 \\
\hline & Filler & 105.5 & 11.3 & 3.2 & 14.7 \\
\hline & Finishing & 104.2 & 11.2 & 3.1 & 14.8 \\
\hline \multirow{3}{*}{ A3 } & Root & 102.1 & 10.9 & 3.6 & 12.2 \\
\hline & Filler & 105.3 & 11.3 & 3.2 & 14.3 \\
\hline & Finishing & 104.9 & 11.6 & 3.2 & 15.0 \\
\hline \multirow{3}{*}{ A4 } & Root & 98.3 & 10.5 & 3.9 & 10.3 \\
\hline & Filler & 105.1 & 11.3 & 3.3 & 14.2 \\
\hline & Finishing & 105.0 & 11.5 & 3.2 & 14.7 \\
\hline \multirow{3}{*}{ B1 } & Root & 150.5 & 12.1 & 7.5 & 9.5 \\
\hline & Filler & 150.4 & 11.9 & 5.6 & 12.4 \\
\hline & Finishing & 149.1 & 11.8 & 7.2 & 9.5 \\
\hline \multirow{3}{*}{ B2 } & Root & 150.6 & 11.8 & 8.3 & 8.3 \\
\hline & Filler & 150.6 & 11.8 & 7.7 & 9.5 \\
\hline & Finishing & 150.5 & 12.2 & 6.5 & 10.9 \\
\hline \multirow{3}{*}{ B3 } & Root & 150.6 & 11.9 & 7.7 & 9.1 \\
\hline & Filler & 150.5 & 12.2 & 7.2 & 9.9 \\
\hline & Finishing & 150.5 & 11.8 & 7.8 & 9.0 \\
\hline \multirow{3}{*}{ B4 } & Root & 150.6 & 11.7 & 6.8 & 10.0 \\
\hline & Filler & 150.6 & 11.9 & 8.3 & 8.4 \\
\hline & Finishing & 150.4 & 11.8 & 7.3 & 9.5 \\
\hline
\end{tabular}




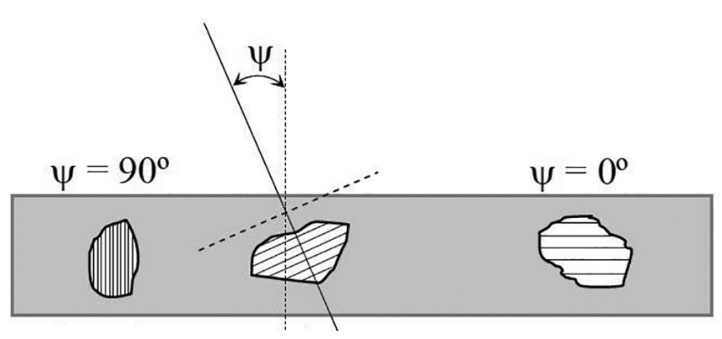

Figure 2: Schematic diagram showing compressive stress in a polycrystalline and isotropic material ${ }^{39}$.

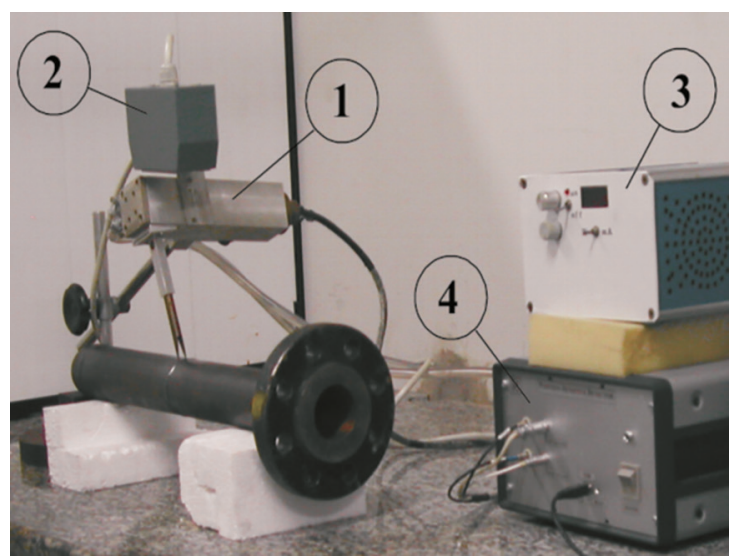

Figure 3: Portable X-ray mini-diffractometer for field measurements (1) Chromium anode X-ray tube; (2) X-ray detector; (3) High-voltage power supply; (4) Control system.

to the propagation of fatigue cracks and stress corrosion cracking $^{42}$, but also due to the physical limitations of the equipment.

The measurements were carried out on the external surface previously prepared with electrolytic polishing. The region analyzed in all cases was in reference to the plane position of the weld deposition. Adjustments on the curves using the analytical function Pearson VII ${ }^{40}$ were carried out for correct localization of the diffraction peak. The maximum X-ray measurement errors varied approximately $\pm 30 \mathrm{MPa}$.

The microstructural characterization of the welded joints were carried out by metallographic examinations. Samples were ground with silicon carbide papers from 220 down to 1000 grade, mechanically polished with $3 \mu \mathrm{m}$ diamond pastes and further electrochemically polished with perchloric acid solution using a current density of $3.75 \mathrm{~A} / \mathrm{cm}^{2}$ for $10 \mathrm{~s}$. The etching was performed using an alcoholic solution with $2 \%$ of nitric acid (Nital 2\%). Microstructural characterization was done with a Jenaplan/Karl Zeiss optical microscope and an XL Phillips ${ }^{\circledR}$ scanning electron microscope (SEM) equipped with an energy dispersive X-ray (EDX) system. Microhardness profiles were made on cross-section of welded joints near inner and outer surfaces using a Shimadzu micro-durometer.

\section{Results and discussion}

\subsection{Residual stress evaluation}

The results of residual stress of the four samples welded with high heat input (Group A) and measured by X-ray diffraction on the outer surface of the butt-welded pipes are presented in Figure 4. In general, the residual stress profile presented a similar behavior, being characterized by compressive stresses in the region of the weld (FZ and HAZ) and tensile stresses in the adjacent area (Base metal). This stress behavior is normally found on the outer surface of welded pipes in butt joints. Similar results are found in literature for carbon steel pipe welded joints measured by other techniques such as hole drilling and ultrasound ${ }^{43}$.

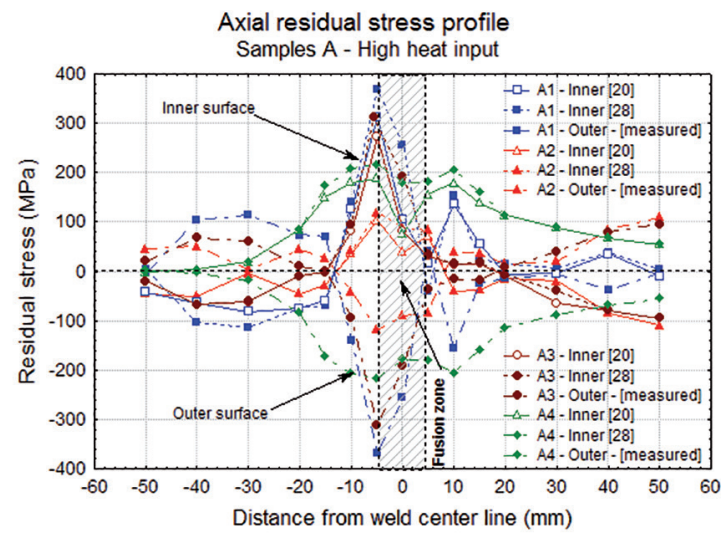

Figure 4: Residual stress profiles - Samples of the group A (high heat input).

Also it is presented in Figure 4 the residual stress profile estimated for inner surface, considering a linear behavior of stress variation through-the-thickness, according recommended by ASME $\operatorname{code}^{28}$, and for non-linear behavior which was found in the technical literature ${ }^{20}$. These extrapolations for inner surface residual stress were carried out as recommended by the ASME XI ${ }^{28}$, which considers that the axial residual stress varies linearly through the thickness, from compressive stress on the outer to tensile stress on the inner surface, but with the same magnitude of the yield strength for both surfaces.

The results published by Brickstad \& Josefson ${ }^{20}$ showed that the residual stress on the inner surface in the HAZ region was $13 \%$ less when compared to the outer surface and that in the center of weld bead (weld metal) the decrease of the axial residual stress was more significant, with a $100 \mathrm{MPa}$ difference, which means a reduction of approximately $58 \%$. However, on all occasions all the stresses are tensile on the inner surfaces and compressive on the outer surfaces for thin-walled pipes circumferentially welded. 
The results of the four samples welded with lower heat input (Group B) are presented in Figure 5 which shows a significant difference of stress values between the right and left sides of the HAZ adjacent to the weld bead. High residual stresses levels were observed on the left side. However, on the right side the stress values are less than $-100 \mathrm{MPa}$, except for sample A4 that presents a very distinct behavior. Also three of the four curves (A1-A3) shown here become tensile around $\mathrm{X}=-15 \mathrm{~mm}$. On the right side, there is a similar behavior between the $\mathrm{A} 1$ and $\mathrm{A} 3$ sample curves that become tensile when $\mathrm{X}=20$.

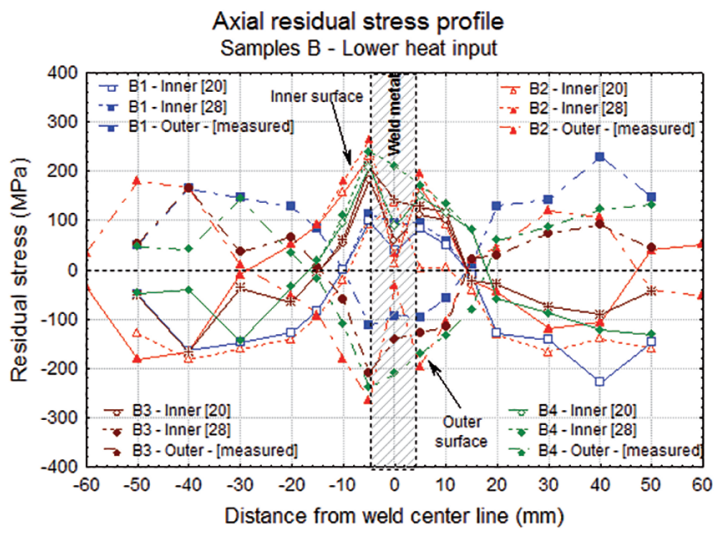

Figure 5: Residual stress profiles - Samples of the group B (low heat input).

In general, the residual stress profiles for group A (high heat input) were similar from the point of view that compressive residual stresses were localized in the weld region (FZ and HAZ) and tensile residual stresses further from the bead while the maximum stress in the HAZ was adjacent to the weld bead. An inverse behavior for the inner surface is expected as shown in the Figure 5, where high tensile residual stress levels were in the weld region, especially on left side and compressive residual stresses were on the base metal. High levels of tensile residual stresses in the weld zone could represent a critical condition, since when the internal surface is in contact with a corrosive fluid, stress corrosion cracking problems can occur ${ }^{20,24}$.

However, the behavior of the extension of regions under tensile and under compression and the levels of the maximum stress were very distinct. The samples A1 and A3 presented very similar stress profiles, showing very similar values for the extension zone under tensile and the maximum residual stress. While the behavior of the A2 and A4 sample stress profiles was very particular with completely different maximum residual stress and extension of regions under compression (outer) and tensile (inner).

Samples of the B group (4" diameter pipes welded with low heat input) showed a very similar behavior, as can be seen in Figure 5. The stress profile of B1, B3 and
B4 presented a good uniformity amongst themselves. In all cases, the maximum tensile residual stresses were localized in the HAZ adjacent to the weld bead. Also the residual stresses in the center of the weld and adjacent to it are tensile and become compressive around $\mathrm{X}=$ $20 \mathrm{~mm}$ for both sides of the welded joint, indicating a tensile stress zone extension of approximately 40 mm. The samples B2, B3 and B4 presented values of maximum tensile residual stress very close, varying between 180 to $250 \mathrm{MPa}$.

When compared to the samples welded with high welding heat input, there was a decrease in the maximum tensile stress levels for the samples welded with low heat input, as can be seen in Figure 4 and 5. Considering the extrapolation to the inner surface, maximum tensile residual stress levels of $252 \mathrm{MPa}^{28}$ and $230 \mathrm{MPa}^{20}$ it is expected, when welded with low heat input (Group B). However, two of the four samples welded with high heat input (Group A) presented tensile stress levels dangerously close to yield stress $\sigma_{\mathrm{Al}}=$ $355 \mathrm{MPa}$ e $\sigma_{\mathrm{A} 3}=313 \mathrm{MPa}\left(\sigma_{\mathrm{y}}=357 \mathrm{MPa}\right)$.

Evaluation of the effect of welding heat input on the axial residual stress through the comparison among the stress profiles of the samples welded with high and low heat input were made. In the weld region a high stress value for the inner surface could be seen for samples welded with high heat input (Group A). While the samples welded with low heat input (Group B) had a smaller level of residual stress, as well as a greater uniformity of the stress profile.

According Silva and Farias ${ }^{26}$, this significant change in the behavior of residual stresses can be attributed to the fact that the welding was carried out manually and perhaps more importantly to the deliberate choice of welding parameters that led to an especially critical condition, in which the thermal contribution was high and the operational conditions for the welder were not appropriate. However, it must be pointed out that the parameters used in this work are within the established range of conventional procedures for pipe welding.

This reveals an instability in the process of generating residual stresses, which also makes it difficult to establish the relation between the thermal contribution of the weld and the residual stress level. This is because, during welding with a low current level, the weld velocity has to be much slower to ensure the correct filling of the joint, resulting in a high thermal contribution. These conditions were reported by the welder, who considers them more tiring and harder to control the weld pool, especially at the root and the finish pass.

Acevedo and co-workers ${ }^{44}$ carried out a residual stress investigation by neutron diffraction measurements in a C-Mn steel weldment. Results have shown that transverse residual stress magnitude was close to or equal to the yield strength of the steel, similar to results obtained in this study. 


\subsection{Microstructure analysis}

This section presents a brief comment on the microstructures formed in the fusion zone (FZ) and heat affected zone (HAZ). A macrograph of the cross-section welded joint are shown in Figure 6 (Group A - Higher heat input) and in Figure 7 (Group B - Lower heat input). In addition is shown an evolution of the microstructure along the inner and outer surface, corresponding to root and finish passes, respectively.

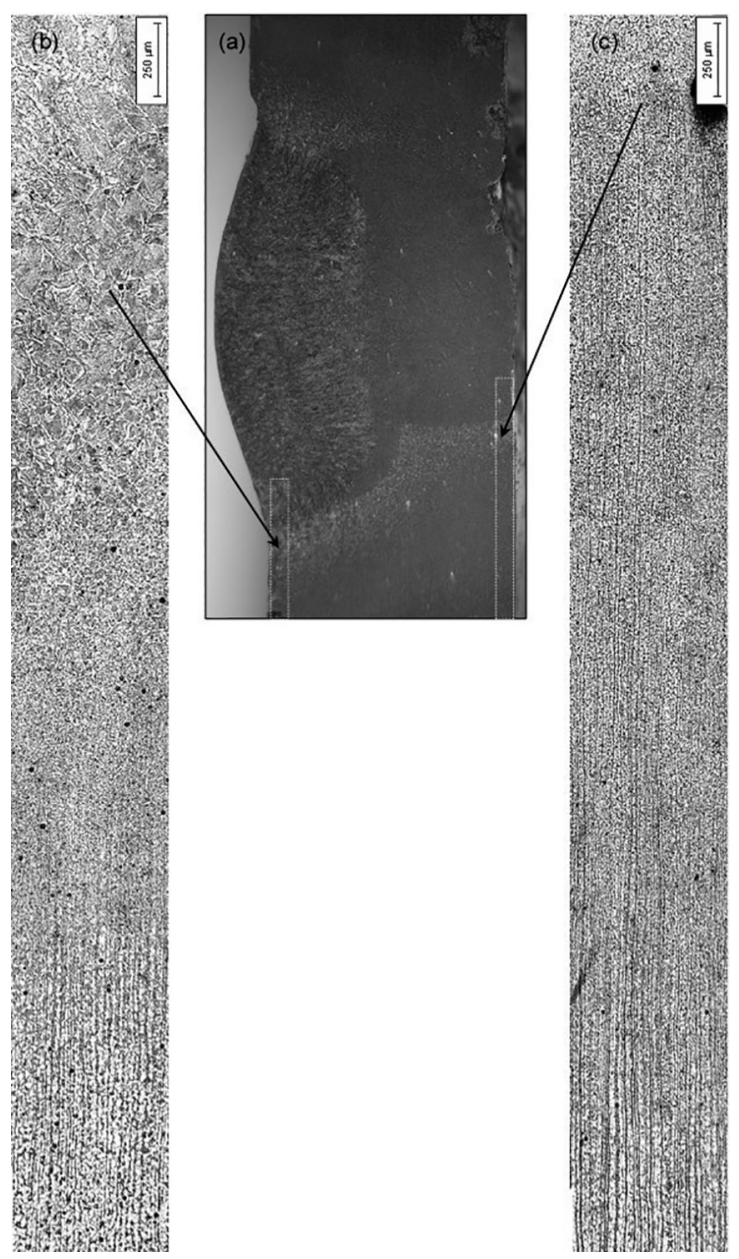

Figure 6: (a) Weld cross-section macrograph of the sample A4. Variation of HAZ microstructure along the outer surface (b) and inner surface (c).

The Figure 8a shows the microstructure of the FZ for a sample welded with high heat input (SampleA4). Several microconstituents, mainly grain boundary allotriomorphic ferrite $\mathrm{F}(\mathrm{GBA})$, polygonal ferrite (PF), acicular ferrite (AF), Widmanstätten ferrite, ferrite plus carbides and in some cases pearlite $\mathrm{FC}(\mathrm{P})$ were seen. This typical microstructure was the same for the Sample B in terms of microconstituents, as seen in Figure 9a.

In the coarse grain heat affected zone (CG-HAZ) microstructure (Figure $8 \mathrm{~b}$ ) proeutectoid ferrite grains are

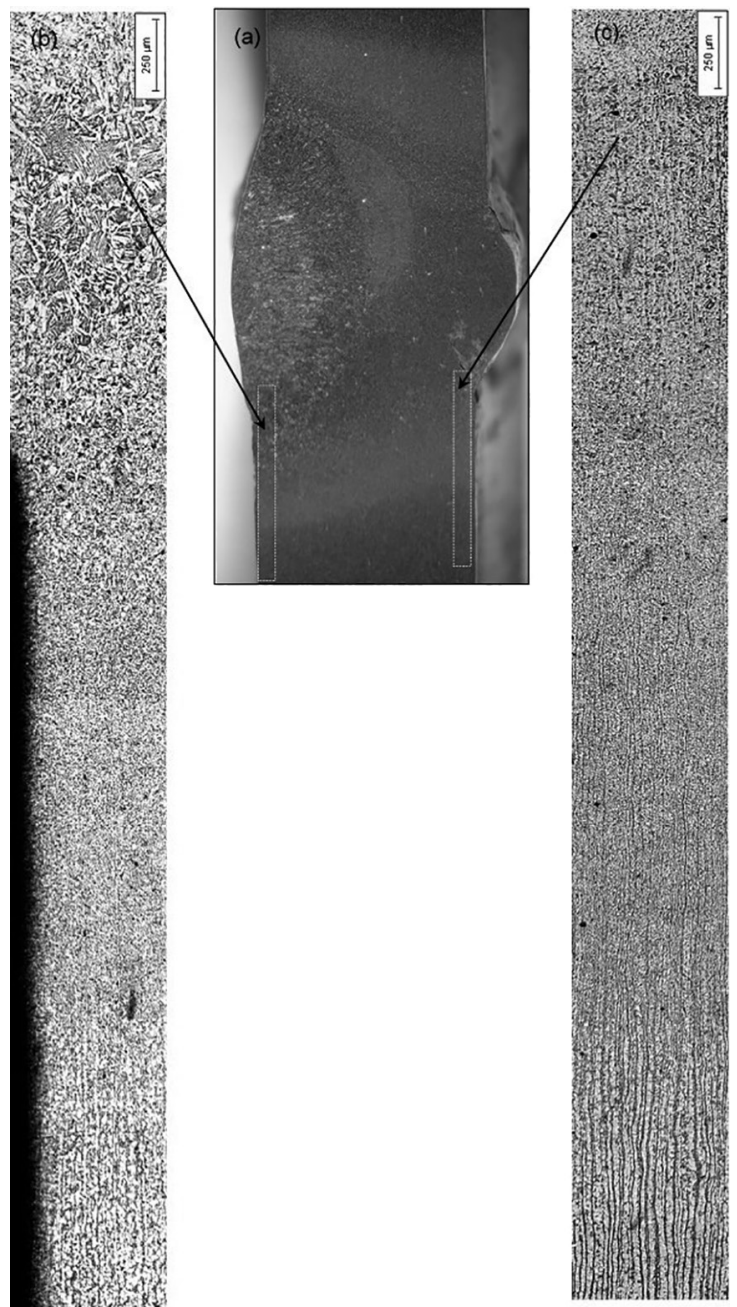

Figure 7: (a) Weld cross-section macrograph of the sample B4. Variation of HAZ microstructure along the outer surface (b) and inner surface (c).

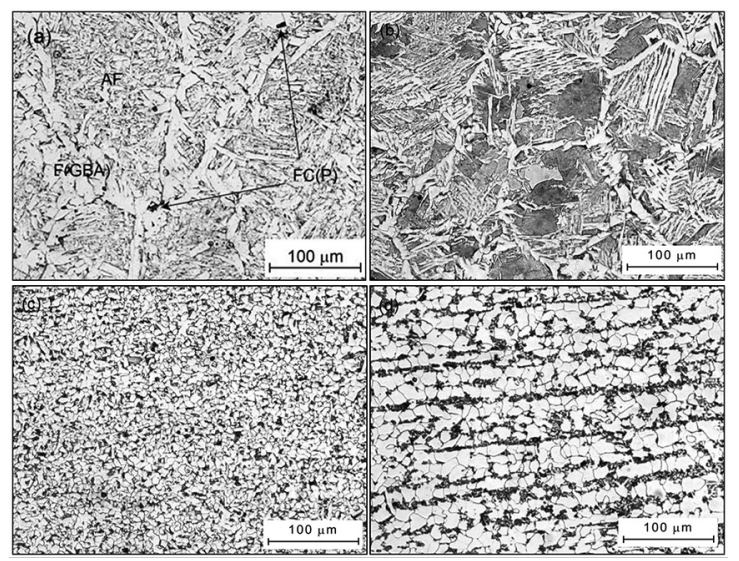

Figure 8: Micrograph from outer surface region of the sample A4 showing representative microstructure of the weld. (a) Fusion zone; (b) CG-HAZ; (c) FG-HAZ; (d) SC-HAZ. Etching: nital 2\%. Magnification: 200X. 


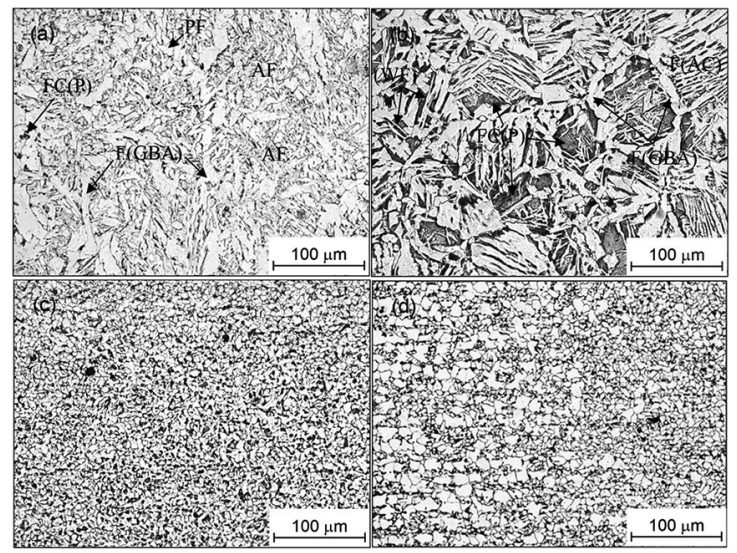

Figure 9: Micrograph from outer surface region of the sample B4 showing representative microstructure of the weld. (a) Fusion zone; (b) CG-HAZ; (c) FG-HAZ; (d) IC-HAZ. Etching: nital 2\%. Magnification: 200X.

distributing along the prior austenite grain boundary, giving also as typical morphologies grain boundary allotriomorphic ferrite $\mathrm{F}(\mathrm{GBA})$ and polygonal ferrite $(\mathrm{PF})$. Also the presence of pearlite in the interior of prior austenite, as well as ferrite with second phase aligned, which is denominated by Alé, Jorge and Rebello ${ }^{45}$ as ferrite with martensite/austenite/ carbides aligned $\mathrm{F}(\mathrm{AC})$ were seen. The typical grain growth occurred at this region is due to the high temperatures achieved during welding heating cycle, which allows the complete austenitization of the grains and its fast growth. Even during a short time to exposure at high temperature, the non-equilibrium condition found at high temperatures (above $1.200^{\circ} \mathrm{C}$ ) is enough to enable the process. The subsequent rapid cooling is the responsible to produce the microstructures commented previously. The same microstructural characteristics were observed to CG-HAZ for Sample B, as can be seen in Figure 9b.

The fine grain heat affected zone (FG-HAZ) microstructure showed a lot of refined grains of ferrite and perlite. The microstructure was composed in their majority by polygonal ferrite $(\mathrm{PF})$ and fine perlite $\mathrm{FC}(\mathrm{P})$ as seen in the Figure 8c, which indicated a recrystallization process occurred during the welding heating cycle. However, at this region both, peak temperature and cooling rate, were lower than CG-HAZ, which allow a complete austenitization, but suppresses the growth of grains. In addition, the subsequent phase transformation from austenite to proeutectoid ferrite and posterior perlite, it is accompanied by a process of intensive nucleation rate with slow rate of growth, resulting in a microstructure with small grain size, lower than the original base metal. The same behavior was found to Sample B (Figure 9c).

The intercritical heat affected zone (IC-HAZ) is formed during the heating of a portion of the material at low temperatures, having as lower limit the Ac1 line and as higher limit the Ac3 line. In this case, the material will experience a partial austenitization, in which the perlite and some ferrite grains together the perlites will undergo this transformation (to austenite), remaining the rest of ferrite unchanged. Thus, a partial grain refinement occurs at this region, as can be seen in Figure 9d. Depending on cooling rate, the austenite formed can transform to martensite, for example. However, in the present study non martensite was found at this region, remaining the microstructure constituted by ferrite and perlite, indicating that the cooling rate was not enough to promote the martensite transformation. The last region is the sub-critical heat affected zone (SC-HAZ), whose the microstructure presented a spheroidization of cementite as the main characteristic (Figure $8 \mathrm{~d}$ ), causing a change in the pearlite morphology, which is known in the literature as a degenerated pearlite ${ }^{45}$.

The microstructure observed in the FZ and CG-HAZ of the root pass (inner surface of the pipe) is presented in Figure 10 (Sample A) and in Figure 11 (Sample B). In both regions the welding heat cycle changed the microstructure causing an intense grain refinement and changes in grain morphology, forming a polygonal structure. This grain refining, which was more effective (efficient) in the root pass weld metal, as shown in Figure 10a, was formed by polygonal ferrite and fine perlite. In the root CG-HAZ there was also a beneficial effect, from the point of view of the microstructure, with a significant grain refining and phase transformation due to the welding heat cycle combination among the root, filler and finishing passes (Figure 10b). The same behavior of the microstructure of the sample A4 was observed for the condition of low heat input, as can be seen in Figure 11. In none of the appraised cases martensite was observed in the HAZ.

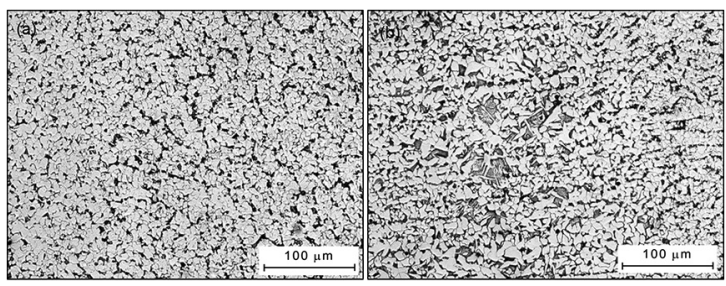

Figure 10: Micrograph from inner surface region (root pass) of the sample A4 showing representative microstructure of the weld. (a) Fusion zone with refined microstructure formed by equiaxial ferrite and perlite grains due to reheating caused by deposition of filler and finish passes; (b) microstructure of the CG-HAZ root pass refined by the subsequent passes. Etching: nital 2\%. Magnification: $200 X$.

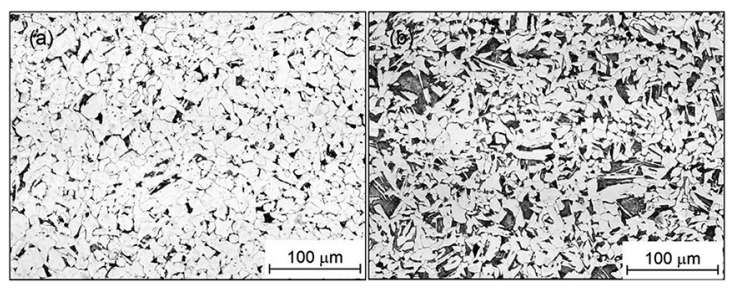

Figure 11: Micrograph from inner surface region (root pass) of the sample B4 showing representative microstructure of the weld. (a) Fusion zone with refined microstructure formed by equiaxial ferrite and perlite grains due to reheating caused by deposition of filler and finish passes; (b) microstructure of the CG-HAZ root pass refined by the subsequent passes. Etching: nital 2\%. Magnification: 200X. 
The interpretation of the stress distributions in the weld region based on microstructures is complicated by the fact that the residual stresses must have a contribution of shrinkage, sudden cooling of surface and phase transformation, and in the case of pipes due to geometry, being a balance of all contributions over the weld section. Thus, according Dai et al. ${ }^{46}$, the stresses distribution may not be explained solely in terms of the local transformation temperature in the weld regions.

Based on microstructural analysis presented earlier, the main microconstituents are several kinds of ferrite changing in morphology, ferrite with secondary phase aligned which may be assumed as a type of bainite, and also perlite. The phase transformation behaviour to origin these microconstituents can significantly affect accumulation of stresses during welding ${ }^{9}$. The mechanism of transformation in steels based on diffusion controlled reconstructive e.g. austenite to ferrite/ pearlite is an isotropic volume change and takes place at higher temperatures typically around $500-650^{\circ} \mathrm{C}^{47}$.

According Dai et al. ${ }^{46}$, at high temperatures, the strains are accommodated by inelastic deformation of the material, and the stress supported by the component follows the yield strength of the material. However, when the component is cooling, the transformation takes place, the transformation strains, as well as any associated transformation plasticity, act to reduce the tensile strains, which can even reverse sign. Even after the transformations be completed, the component continues to shrink, which result in the introduction of tensile stresses at a rate that is determined by the expansion coefficient of the ferrite ${ }^{46}$.

Another question that is necessary to be considered is the geometry of the component, which is a pipe. As commented previously, the expansion and contraction, and its particular restriction behavior are quite complex. The bending effect caused by tourniquet effect may contribute significantly to introduce the stress profile found in this study.

\subsection{Microhardness}

Microhardness profiles in the transverse section of the welded joint were evaluated for each heat input. The profiles extended from the base metal through the HAZ, fusion zone and HAZ again until the base metal on the other side of the joint. The microhardness profiles of the inner and outer surfaces along all the joints were determined as can be seen in Figures 12 and 13. An evaluation of the microhardness profile of the outer surface shown an elevation of the hardness is observed in the central portion, which corresponds to WM. In general, the HAZ hardness was inferior to the WM. The arrows indicate the transition zone between the WM and HAZ. The higher hardness of the WM can be attributed to the presence of ferrita acicular and the greater yield strength Kim et al. ${ }^{48}$.

The inner surface suffered a decrease in hardness, probably caused by the phase transformations produced due

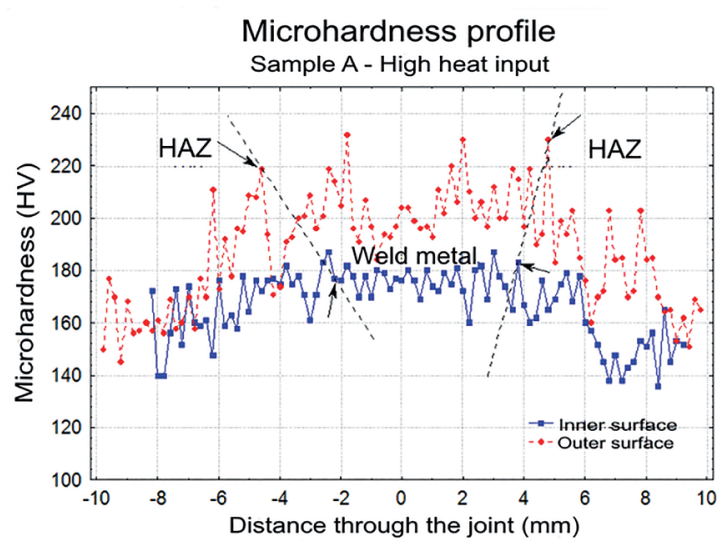

Figure 12: Microhardness profile along cross-section for the sample A4 welded with high heat input.

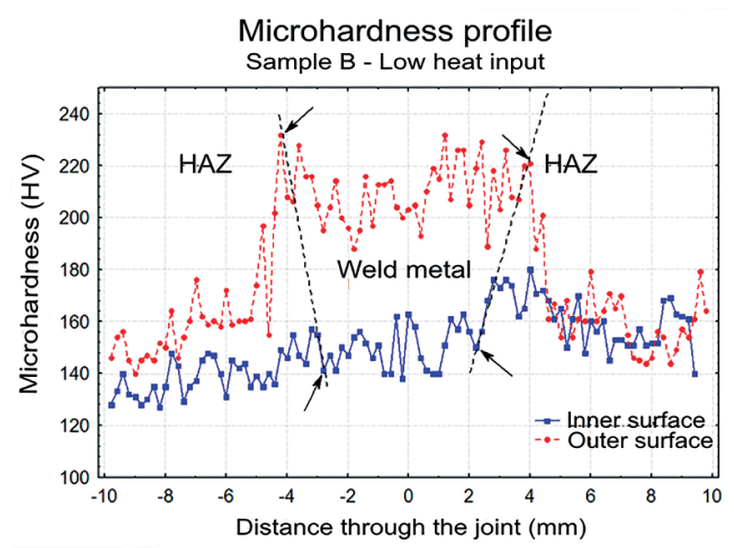

Figure 13: Microhardness profile along cross-section for the sample B4 welded with low heat input.

to the heating cycle of the subsequent passes. Both WM as HAZ were favored by the thermal effect, showing values of hardness in the root of the joint well below $200 \mathrm{HV}$, which is very inferior to the maximum allowed (248 HV). Also no point analyzed arrived close to the hardness value limit established by the standard.

The microhardness profile along the weld bead for the inner and outer surfaces of sample B4 is presented in Figure 13. Again the WM presented higher hardness levels when compared to the HAZ and base metal for the outer surface. For the inner surface there was an accentuated fall of hardness, especially in the WM and CGHAZ, which can be attributed to the phase transformations that occurred in these areas. These results are quite positive, because they show that from the point of view of hardness that this procedure is capable of reducing such a mechanical property (hardness) and therefore would eliminate the need for post weld heat treatment (PWHT).

However, as mentioned previously, some works have reported the occurrence of failures in industrial piping due to hydrogen sulfide stress corrosion cracking (HSSCC), although 
in some cases the cracks are located in low hardness areas. Barbosa et al. ${ }^{33}$ evaluated the microstructure and hardness of ASTM A106 Gr. B steel pipes used in a hydrodesulphurization unit in an oil refinery, which failed in service due to problems related to HSSCC and hydrogen embrittlement.

In another work, Azevedo ${ }^{36}$ presented results of the failure analysis of a crude oil pipeline of API 5L X46 steel. The author confirmed that the hardness level of the welded joint was below the critical limit for SCC, which is 248 or $250 \mathrm{HV}^{32}$. He concluded that the pipeline failure was a stressoriented hydrogen-induced cracking (SOHIC) mechanism, which occurred due to the influence of residual or applied tensile stresses and whose crack is aligned perpendicular to application stress directions.

Lee and co-workers ${ }^{49}$ studied the cause of failure of an ASTM A53 Grade B carbon steel pipe used in a condensate pipeline, which cracked after six months in service. The EDS analysis indicated the presence of chlorine and sulfur in the cracked surface, which indicated that the cracked area was subjected to a corrosion process, being these elements associated to SCC caused by service environment. However, the results of hardness obtained by the authors ${ }^{49}$ along the surface cracked cross-section were very low, ranging from $166 \mathrm{HV}$ to $184 \mathrm{HV}$, which are well below to 248 or 250 $\mathrm{HV}$ reported by literature as the critical hardness to SCC in carbon steels ${ }^{32}$. The residual stress close to cracking was estimated using instrumented indentation test, in which 216 $\mathrm{MPa}$ was measured. The authors concluded that the pipe failed by SCC mechanism, being the tensile residual stress in the weld the major cause of SCC occurrence.

Recent investigation performed by Ruminski ${ }^{50}$, on the root causes of failure of an ASTM A106 carbon steel pipe from component cooling water system at a nuclear power station, concluded that the failure and damage was due to the outcomes of a susceptible microstructure (small areas of pearlite on ferrite grain boundaries) in combination with residual tensile stresses from welding, and surface contamination, not detectable by EDS, such as hydroxides. Also in this case the hardness in the cracked area was 139 $\mathrm{HV}$, and $123 \mathrm{HV}$ in base metal, both below to $248 \mathrm{HV}$ or $250 \mathrm{HV}$ critical hardness.

These observations regarding the residual stresses, hardness and stress corrosion cracking show that this subject matter is not well understood, requiring efforts to carefully evaluate the correlation between these properties/characteristics. The present work shows that, if only hardness is considered for the evaluation of stress corrosion cracking (SCC) susceptibility in welded joints, the results could be misguiding, because according to the welding residual stress analysis carried out in this work, there were high levels of tensile residual stress in WM and HAZ, even when the hardness was well below the standard limit.

Another important observation is that in order to assure a low level of hardness of the welded joint, does not necessarily need a low level of residual stress. This information is fundamental for the project and maintenance engineering areas, because the elaboration of welding procedures and specification of PWHT is many times only based on the hardness criteria, which does not necessarily lead to a favorable condition from the point of view of residual stresses.

\section{Conclusion}

Based on the experimental results of the residual stress profiles, microstructure and hardness measurements in welded steel pipes by the manual GTAW process, it is possible to conclude that an increase in welding heat input affects the behavior of the residual stress profiles. Showing a tendency that when the weld heat input is increased residual stress levels increase. Microstructural changes due to the welding heat cycle were not able to promote the formation of a brittle microstructure, such as martensite. A satisfactory combination between root and finishing pass was obtained for both conditions (high and low welding heat input), promoting a significant grain refining of the HAZ and fusion zones and also causing a decrease in the hardness values. Independent of the welding condition applied, no sample evaluated showed hardness values above the critical (maximum) value indicated by standard. This shows that if a welded joint presents low hardness levels it does not necessarily represent low residual stress conditions.

\section{Acknowledgments}

The authors are grateful to Prof. Dr. Vladmir I. Monin for their collaboration and for the use of the laboratory facilities at IPRJ-UERJ. To Laboratory of Welding Research and Technology (LPTS-UFC) and Materials Characterization Laboratory (LACAM-UFC) laboratories for their support to the experiments. To PETROBRAS (LUBNOR and CENPES) for their collaboration and the Brazilian research agencies (CNPq, CAPES, FINEP and ANP/PRH-31) for financial support.

\section{References}

1. Mochizuki M, Hayashi M, Hattori T. Residual stress distribution depending on welding sequence in multi-pass welded joints with X-shaped groove. Journal of Pressure Vessel Technology. 2000;122(1):27-32.

2. Mochizuki M, Hattori T, Nakakado K. Residual stress reduction and fatigue strength improvement by controlling welding pass sequences. Journal of Engineering Materials and Technology. 2000;122(1):108-112.

3. Miyazaki K, Mochizuki M, Kanno S, Hayashi M, Shiratori M, Yu Q. Analysis of stress intensity factor due to surface crack propagation in residual stress fields caused by welding (Comparison of influence function method and inherent strain analysis). JSME International Journal, Series A: Solid Mechanics and Material Engineering. 2002;45(2):199-207. 
4. Moura EP, Silva RR, Siqueira MHS, Rebello JMA. Pattern Recognition of Weld Defects in Preprocessed TOFD Signals Using Linear Classifiers. Journal of Nondestructive Evaluation. 2004;23(4):163-172.

5. Fortunko CM, Schramm RE. Evaluation of pipeline girth welds using low-frequency horizontally polarized waves. Journal of Nondestructive Evaluation. 1982;3(3):155-173.

6. Cadwallader L, Pinna T. Reliability Estimation for Double Containment Piping. Fusion Science and Technology. 2013;64(2):351-356.

7. Ditchburn RJ, Burke SK, Scala CM. NDT of welds: state of the art. NDT \& E International. 1996;29(2):111-117.

8. Withers PJ. Residual stress and its role in failure. Reports on Progress in Physics. 2007;70(12):2211.

9. Withers PJ, Bhadeshia HKDH. Residual stress. Part 2 - Nature and origins. Materials Science and Technology. 2001;17(4):366-375.

10. Radaj D. Heat effects of welding: temperature field residual stress distortion. Berlin: Springer-Verlag; 1992.

11. Mochizuki M. Control of welding residual stress for ensuring integrity against fatigue and stress-corrosion cracking. Nuclear Engineering and Design. 2007;237(2):107-123.

12. Nguyen TN, Wahab MA. A theoretical study of the effect of weld geometry parameters on fatigue crack propagation life. Engineering Fracture Mechanics. 1995;51(1):1-18.

13. Nguyen TN, Wahab MA. The effect of undercut and residual stresses on fatigue behavior of misaligned butt joints. Engineering Fracture Mechanics. 1996;55(3):453-469.

14. Nguyen TN, Wahab MA. The effect of weld geometry and residual stress on the fatigue of welded joints under combined loading. Journal of Materials Processing Technology. 1998;77(1-3):201-208.

15. Leis BN, Eiber RJ. Stress-Corrosion Cracking On Gas-Transmission Pipelines: History, Causes and Mitigation. In: Proceedings of First International Business Conference on Onshore Pipelines; 1997 Dec; Berlin, Germany.

16. Delafosse D, Magnin T. Hydrogen induced plasticity in stress corrosion cracking of engineering systems. Engineering Fractures Mechanics. 2001;68(6):693-729.

17. Fessler RR, Krist K. Research challenges regarding stresscorrosion cracking of pipelines. In: Proceedings of CORROSION 2000, Nace Annual Conference, Paper $n^{\circ}$ 370; 2000; Houston, TX, USA.

18. Shirinzadeh-Dastgiri M, Mohammadi J, Behnamian Y, Eghlimi A, Mostafaei A. Metallurgical investigations and corrosion behavior of failed weld joint in AISI 1518 low carbon steel pipeline. Engineering Failure Analysis. 2015;53:78-96.

19. Masouri D, Zafari M. Sulfide stress cracking of tubular product-case histories. In: Proceedings of CORROSION 2005, Nace Annual Conference, Paper $n^{\circ}$ 5460; 2005 Apr 3-7; Houston, TX, USA.

20. Brickstad B, Josefson BL. A parametric study of residual stresses in multi-pass butt-welded stainless steel pipes. International Journal of Pressure Vessels and Piping. 1998;75:11-25.

21. Abid M, Siddique M, Mufti RA. Prediction of welding distortion and residual stress in a pipe-flange joint using the finite element technique. Modelling and Simulation in Materials Science and Engineering. 2005;13(3):455-470.
22. Teng TL, Chang PH. A study of residual stress in multi-pass girth-butt welded pipes. International Journal of Pressure Vessel and Piping. 1997;74(1):59-70.

23. Mochizuki M, Hayashi M, Hattori T. Numerical Analysis of Welding Residual Stress and Its Verification Using Neutron Diffraction Measurement. Journal of Engineering Materials and Technology. 2000;122(1):98-103.

24. Law M, Prask H, Luzin V, Gnaeupel-Herold T. Residual stress measurements in coil, linepipe and girth welded pipe. Materials Science and Engineering: A. 2006;437(1):60-63.

25. Purmohamad H, Kermanpur A, Shamanian M. Numerical Simulation and Experimental Investigation of Residual Stresses in the Circumferential Butt GTAW of Incoloy $800 \mathrm{H}$ Pipes. Journal of Materials Engineering and Performance. 2010;19(1):13-21.

26. Silva CC, Farias JP. Non-uniformity of residual stress profiles in butt-welded pipes in manual arc welding. Journal of Materials Processing Technology. 2008;199(1-3):452-455.

27. Lee $\mathrm{CH}$, Chang KH. Three-dimensional finite element simulation of residual stresses in circumferential welds of steel pipe including pipe diameter effects. Materials Science and Engineering: A. 2008;487(1-2):210-218.

28. Section XI Task Group for Piping Flaw Evaluation, ASME Code. Evaluation of Flaws in Austenitic Steel Piping. Journal of Pressure Vessel Technology. 1986;108(3):352-366

29. Silva CC, Souza Neto AB, Silva FDA, Freitas Júnior FES, Farias JP. Welding of the ASTM A106 Gr. B steel pipes for high temperature service - Part 1 - Residual Stress Analysis. Soldagem \& Inspeção. 2008;13(2):128-140.

30. Silva CC, Souza Neto AB, Silva FDA, Freitas Júnior FES, Farias JP. Welding of the ASTM A 106 Gr. B steel pipes for high temperature service - Part 2 - Microstructure and hardness. Soldagem \& Inspeção. 2008;13(3):127-138.

31. American Petroleum Institute. API 510. Pressure Vessel Inspection Code: Maintenance Inspection, Rating, Repair, and Alteration. Washington: American Petroleum Institute; 1992.

32. ASTM International. ASTM A106. Standard Specification for Seamless Carbon Steel Pipe for High-Temperature Service. West Conshohocken: ASTM International. 2006.

33. International Organization for Standardization. DIN EN ISO 15156-2 standard. Petroleum and natural gas industries Materials for use in H2S-containing environments in oil and gas production - Part 2: Cracking-resistant carbon and low alloy steels, and the use of cast irons. Geneva: International Organization for Standardization; 2003.

34. NACE International. NACE MR-0175. Petroleum and natural gas industries - Materials for use in H2S-containing environments in oil and gas production - Part 2: Cracking-resistant carbon and low alloy steels, and the use of cast irons. Houston: NACE International; 2003.

35. Barbosa C, de Souza SMC, Centeno RO, Abud IC, Ferraz OB. Failure analysis of pipes used in a hydrodesulfuration system of a petrochemical plant. Engineering Failure Analysis. 2006;13(7):1076-1091. 
36. Azevedo CRF. Failure analysis of a crude oil pipeline. Engineering Failure Analysis. 2007;14(6):978-994.

37. Noyan IC, Cohen JB. Residual stress, Measurement by diffraction and interpretation. New York: Springer; 1987.

38. Eigenmann B, Macherauch E. Röntgenographische Untersuchung von Spannungszuständen in Werkstoffen. Teil III. Fortsetzung von Matwiss. und Werkstofftechn. Heft 3/1995, S. 148-160 und Heft 4/1995, S. 199-216. Materialwissenschaft und Werkstofftechnik. 1996;27(9):426-437.

39. Sprauel JM, Castex L. X-ray stress analysis. Materials Science Forum. 1991;79-82:143-152.

40. Assis JT, Monin VI, Pereira FR, Filippov S. Difratômetro de raio-X portátil para análise de tensões em condições de campo. Rio de Janeiro: Instituto Politécnico, UER; 2003.

41. Monin VI, Assis JT, Pereira FR, Filippov S, Gurova T, Teodósio JT, de Abreu HFG. Portable X-ray apparatus for stress measurements. In: Proceedings of SPIE 5400, Seventh International Workshop on Nondestructive Testing and Computer Simulations in Science and Engineering; 2003 Jun 9-15; St Petersburg, Russia. SPIE 5400; 2004. p. 192-195.

42. Hayashi M, Ishiwata M, Morii Y, Minakawa N, Root JH. Residual stress distribution in carbon steel pipe welded joint measured by neutron diffraction. Materials Science Research International. 2000;6(4):287-294.

43. Akhshik S, Moharrami R. Improvement in accuracy of the measurements of residual stresses due to circumferential welds in thin-walled pipe using Rayleigh wave method. Nuclear Engineering and Design. 2009;239(10):2201-2208.
44. Acevedo C, Evans A, Nussbaumer A. Neutron diffraction investigations on residual stresses contributing to the fatigue crack growth in ferritic steel tubular bridges. International Journal of Pressure Vessels and Piping. 2012;95:31-38.

45. Alé RM, Jorge JCF, Rebello JMA. Constituintes Microestruturais de Soldas de Aços C-Mn Baixa Liga. Parte II: Metal de Solda. Soldagem \& Materiais. 1993;5(3):18-25.

46. Dai H, Francis JA, Stone HJ, Bhadeshia HKDH, Withers PJ. Characterizing phase transformations and their effects on ferritic weld residual stresses with X-rays and neutrons. Metallurgical and Materials Transactions A. 2008;39(13):3070-3078.

47. Saraiva DL, Béreš M, Silva CC, Nunes CS, Silva JJM, Abreu HFG. Application of low $\mathrm{M}_{\mathrm{s}}$ temperature consumable to dissimilar welded joint. Materials Science and Technology. 2014;30(9):1057-1062.

48. Kim JH, Oh YJ, Hwang IS, Kim DJ, Kim JT. Fracture behavior of heat-affected zone in low alloy steels. Journal of Nuclear Materials. 2001;299(2):132-139.

49. Lee J, Han S, Kim K, Kim H, Lee U. Failure analysis of carbon steel pipes used for underground condensate pipeline in the power station. Engineering Failure Analysis. 2013;34:300-307

50. Ruminski A. Failure Analysis of a Low-Temperature Carbon Steel Pipe from a Nuclear Power Station Cooling Water System. Journal of Failure Analysis and Prevention. 2015;15(4):534-540. 